\title{
The immune system and microbiome in pregnancy
}

\author{
G.M. Fuhler \\ Erasmus MC University Medical Center Rotterdam, Department of Gastroenterology and Hepatology, Erasmus Medical Center, Gravendijkwal 230, 3015CE, \\ Rotterdam, the Netherlands
}

\section{A R T I C L E I N}

\section{Article history:}

Received 1 October 2019

Received in revised form

19 February 2020

Accepted 5 March 2020

\section{Keywords:}

Pregnancy

Tolerance

Th subsets

Infection

Vaginal microbiome

Intestinal microbiome

Gestational diabetes mellitus

Inflammatory bowel disease

\begin{abstract}
A B S T R A C T
Hormonal changes during pregnancy instigate numerous physiological changes aimed at the growth and delivery of a healthy baby. A careful balance between immunological tolerance against fetal antigens and immunity against infectious agents needs to be maintained. A three-way interaction between pregnancy hormones, the immune system and our microbiota is now emerging. Recent evidence suggests that microbial alterations seen during pregnancy may help maintain homeostasis and aid the required physiological changes occurring in pregnancy. However, these same immunological and microbial alterations may also make women more vulnerable during pregnancy and the post-partum period, especially regarding immunological and infectious diseases. Thus, a further understanding of the hostmicrobial interactions taking place during pregnancy may improve identification of populations at risk for adverse pregnancy outcomes.
\end{abstract}

(C) 2020 Published by Elsevier Ltd.

\section{Introduction}

During pregnancy, the female body undergoes numerous anatomical and physiological changes to allow the successful implantation of a fertilized egg, the growth of an MHC mismatched fetus and timely parturition. Most of these changes are transient, and will revert to 'normal' after delivery. The basis for all these physiological changes lies in rises in hormone levels that take place upon conception. Implantation of a fertilized egg results in the production of human chorionic gonadotrophin (hCG) by placental trophoblasts. Systemic levels of hCG steadily increase to reach peak levels around week 10 of gestation, and drop to baseline values shortly thereafter [1]. hCG initiates the production of progesterone by cells of the corpus luteum, a temporary endocrine structure that remains in the ovary after ovulation. The corpus luteum also produces estrogen, which in turn contributes to progesterone biosynthesis. Production of both progesterone and estrogen are taken over by the growing placenta after several weeks of pregnancy, and their levels thus rise progressively during the first trimester (T1) and reach their peak in the third trimester (T3) of gestation (Fig. 1A).

While the main purpose of hCG has long been considered to be

E-mail address: g.fuhler@erasmusmc.nl. the stimulation of progesterone production, numerous processes are now known to be dependent on hCG activity. In particular, promotion of placental growth and vascularisation appear to be a significant part of hCG functionality. Furthermore, hCG stimulates fetal organ growth and differentiation and prevents premature uterine muscle contraction [2]. Progesterone plays a role in early pregnancy by inducing differentiation of stromal cells into decidual cells, and helps reshape the cervix to adapt it to fetal implantation. Furthermore, progesterone sustains pregnancy by prohibiting uterine contractions through reduction of oxytocin and prostaglandin receptor production, and inhibition of contractibility of smooth muscle cells [3,4]. Estrogens, while not stimulating contraction, do appear to facilitate processes leading up to parturition [5]. Other important functions of estrogens include placental neovascularisation and preparation of breast tissue for lactation [6,7]. In addition to the gross anatomical and physiological alterations initiated during pregnancy, a pivotal role for pregnancy hormones in the modulation of immunological processes throughout pregnancy is emerging, which is essential for the allogenic fetus to grow and thrive.

\section{How to deal with fetal alloantigens}

Upon fertilization of an egg, half of the DNA of the ensuing fusion product is from paternal origin. Thus, the implanted embryo 
A
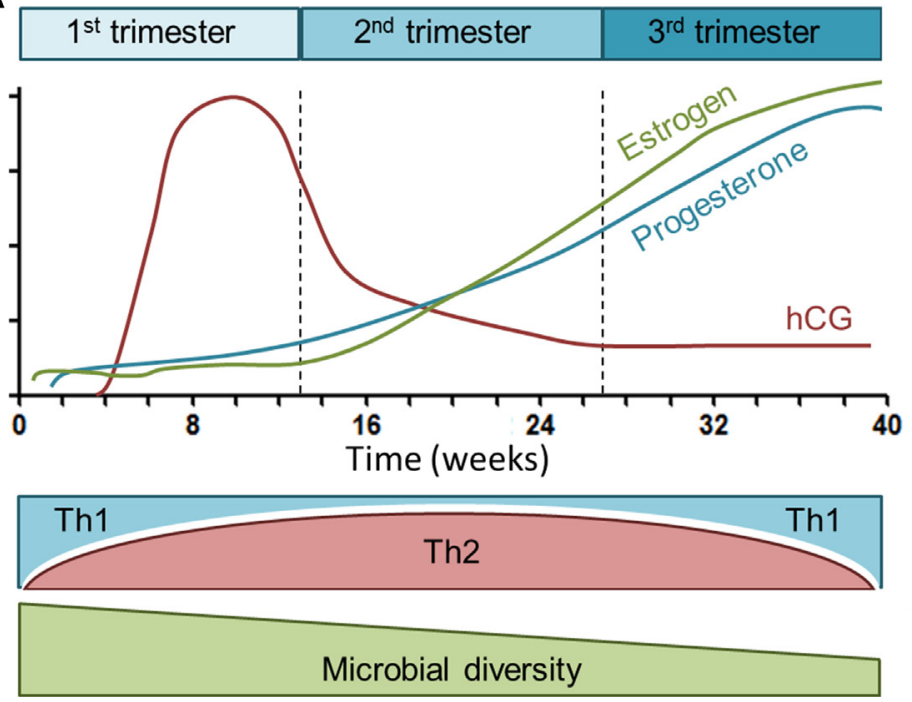

B

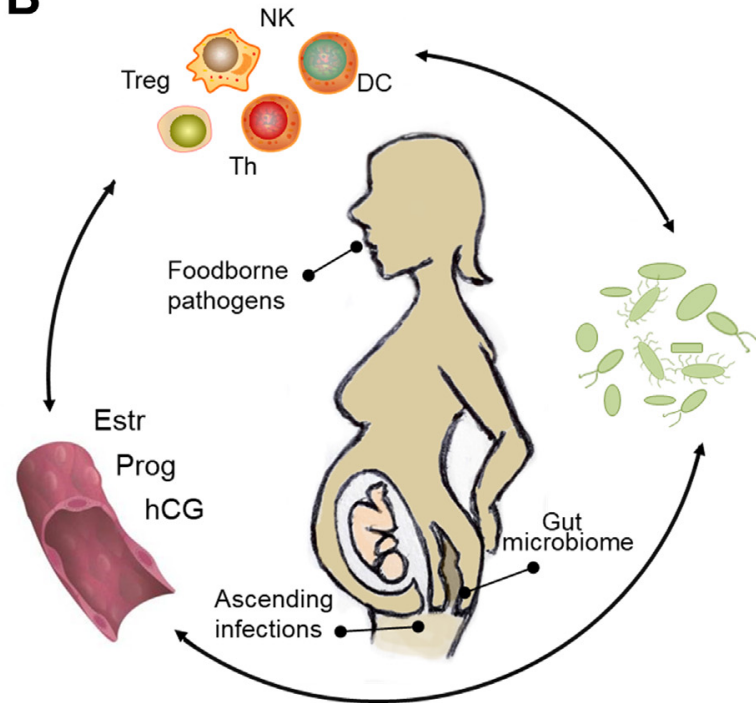

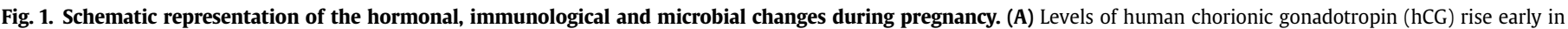

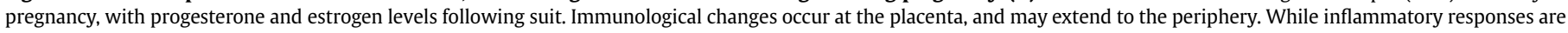

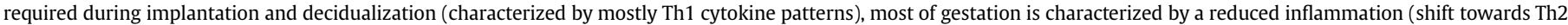

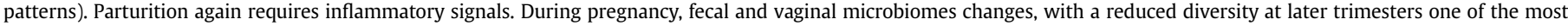

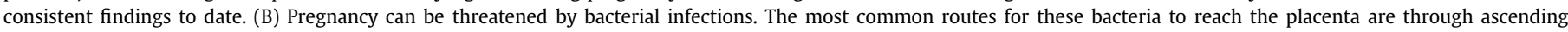

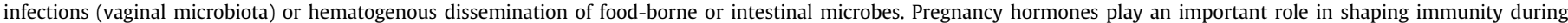

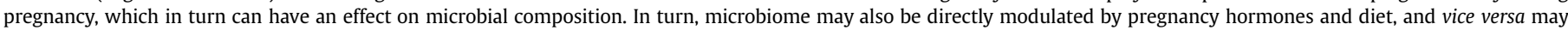
exert their effect on immunological parameters as well as hormone levels.

as well as the fetal placenta express paternal/fetal antigens which can be potentially recognized by the maternal immune system, but are nevertheless tolerated. While the fetal-maternal interface which develops during pregnancy separates the maternal and fetal blood streams, not only nutrients, oxygen and metabolic waste products cross the placental interface from fetus to mother and vice versa. Already in the early sixties it was noted that small numbers of leukocytes and platelets were able to cross the placenta from mother to fetus [8]. In the decade after, fetal cells were also observed in the blood of pregnant women, showing the bidirectionality of cellular transport [9]. This poses the question as to how the maternal immune system deals with such a challenge: fetal antigens and fetal MHC molecules on which they are presented will not be recognized as 'self by the mother's immune system. This in turn means that maternal immunity against the fetus may cause harm to the developing infant. Case in point is rhesus alloreactivity, where a mother who does not possess the red blood cell-expressed rhesus D-antigen ( $\mathrm{Rh}$ ) may develop antibodies against $\mathrm{Rh}$ when pregnant with a Rh + child. This may have disastrous consequences in a subsequent $\mathrm{Rh}+$ pregnancy, due to destruction of fetal red blood cells by maternal antibodies crossing the placenta [10]. Nevertheless, in most cases, pregnancies are not ended by maternal immunological responses, and already in the early 50's Sir Peter Medawar proposed that pregnancy is accompanied by some form of immune-tolerance in order to protect the fetus against the maternal alloresponse [11].

\section{Implantation vs transplantation}

In the search for immunological parameters explaining fetal tolerance in pregnancy, implantation of an allogenic fetus during pregnancy has often been liked to organ transplantation. Several cell types are involved in immunological reactions towards foreign cells. Allogenic cells can be directly recognized by their non-self MHC molecules (either MHC-II on immune cells or MHC-I on most other cell types) by either $\mathrm{CD}^{+}$cytotoxic T-cells or $\mathrm{CD}^{+}$ Thelper (Th) cells. This direct allorecognition causes a rapid expansion of T-cell clones and which can subsequently attack the foreign tissue [12]. Alternatively, foreign cells or their products are taken up by phagocytosing antigen presenting cells (APCs) such as dendritic cells, macrophages and activated B-cells. Intracellular breakdown and processing of foreign cells then takes place, resulting in antigen presentation of foreign MHC-derived antigenic peptides in the context of self MHC-II molecules. These can then be recognized by $\mathrm{CD} 4^{+}$and $\mathrm{CD} 8^{+} \mathrm{T}$-cells, in what is known as the indirect pathway of allorecognition [13]. In turn, activated $\mathrm{CD}^{+}{ }^{+} \mathrm{Th}$ cells will proliferate and differentiate into different Th lineages which can each produce their own array of (pro-)inflammatory cytokines. In addition, $\mathrm{CD}^{+}$cells will activate antigen-specific Bcells to induce antibody production, whereas $\mathrm{CD}^{+}$cytotoxic will kill nucleated foreign cells through self-MHC restricted pathways. The ensuing result is rejection of the tissues carrying the original antigens through antibody and T-cell mediated attack. While in transplantation biology immunosuppressive medication is required to prevent rejection of allografts, a natural immunetolerant state has been proposed to occur during pregnancy to avoid immunological rejection of the fetus.

\section{Immune tolerance in pregnancy - recognition of paternal antigens}

Several maternal immune cell subsets are present at the maternal decidua. The majority of early infiltrating immune cells (>70\%) are natural killer (NK) cells and macrophages recruited by endometrial hCG, progesterone and estrogen [14], but T-cells are also found. The physiological role of NK cells is to kill cells under stress, such as tumor and virally infected cells, and the recognition and lysis of cells lacking self MHC-I. Thus, the presence of large numbers of NK cells in the decidua might be expected to result in cytolysis of the fetal 'missing self' cells, as has been suggested in the 
organ transplantation setting [15]. However, uterine NK (uNK) cells express different cell-surface receptors from peripheral NK cells and are not cytotoxic [16]. This is partly due to the fact that fetal trophoblasts show an a-typical MHC expression, with and some of these (human histocompatibility leukocyte antigen [HLA]-E, G and F) actively suppressing uNK activity [17]. In addition, fetal trophoblasts are lacking in several other MHC-I and II molecules, which means they can to some extent escape recognition by the maternal immune system [18]. However, this MHC decrease does not appear to be the predominant factor in maternal-fetal tolerance, as tolerance is maintained even when paternal MHC is artificially reexpressed [19]. Studies on human third trimester decidual T-cells indicate that these cells do proliferate in response to fetal challenge in vitro [20], suggesting that recognition of paternal antigens does occur [21]. Mouse studies have indicated that T-cell responses to paternal antigens expressed by trophoblasts also occur at the placental interface, but that these are limited to indirect allogen recognition [22]. This means that maternal APCs are required in order to present fetal antigens to maternal T-cells, rather than direct recognition of intact fetal MHC molecules by maternal immune cells, which may severely limit the immune reactivity [23]. In addition, several mechanisms are in place to ensure that decidual APCs are less efficacious as compared to their peripheral counterparts. Decidualisation of the endometrium reduces the number of dendritic cells (DCs), one of the most efficient APC, and immobilizes remaining DC to prevent their T-cell activating properties [24]. In vitro, hCG is able to stimulate peripheral blood DC subsets to maintain a tolerant phenotype [25]. Together, these data suggest that limited recognition and response to fetal cells both contribute to fetal tolerance during pregnancy.

\section{Immune tolerance in pregnancy - T-cell subsets}

In addition to reduced recognition of alloantigens, the response of resident immune cells to activating triggers is also modulated via alternative mechanisms. It has been suggested that maternal T-cells themselves may acquire a state of tolerance against paternal alloantigens [26]. This may be in part be due to the presence of regulatory T-cells (Treg), a subset of T-cells that limit proliferation of $\mathrm{CD}^{+}$and $\mathrm{CD}^{+}$T-cells compartments via production of antiinflammatory cytokines such as IL-10 and transforming growth factor (TGF)- $\beta$ [27]. Up to $20 \%$ of decidual T-cells are composed of Tregs, which have the capacity to suppress fetal alloresponses [28]. These cells may be actively recruited from the peripheral blood [29], or local expansion of Tregs can be induced by trophoblastderived IL-10 [30]. Growth factors released by the placenta also induce a shift in differentiation of macrophages from an inflammatory phenotype (M1) to a wound-healing phenotype (M2), which further increases local IL-10 production [31]. M2 macrophages, as well as trophoblasts and DCs, are also an important source of the soluble enzyme indoleamine 2,3,-dioxygenase (IDO1) [16], which is required for the suppression of T-cell-induced local inflammatory reactions against fetal alloantigens [32]. This enzyme converts the essential amino acid tryptophan (Trp) into kynurenine, which has the dual effect of inducing apoptosis of $\mathrm{CD}^{+} \mathrm{T}-$ cells by Trp depletion, and skewing $\mathrm{CD} 4^{+}$T-cells to Treg differentiation [33]. Thus, local decidual responses are all geared towards the production of regulatory T-cells.

Tregs are not the only effector T-cells to be modulated during pregnancy, and a lot of attention has been directed towards the different Thelper (Th) cell subsets present during pregnancy. Traditionally, Th cells were divided into two subclasses, Th1 and Th2, based on their differential capacity to produce cytokines [34]. More recent evidence suggests that this distinction was somewhat crude, and additional Th populations (e.g. Th17, Th22, Th9) have now been identified. Th1 cells are mostly associated with IFN $\gamma$ production and responses to intracellular pathogens and viral infections, whereas Th2 cells specifically produce IL-4, IL-13 and IL-5 and form the main response to helminths [35]. During pregnancy, IL-25, an IL-17 family member expressed by decidual T-cells, NK cells, Tregs and macrophages, stimulates the production of IL- 4 and IL-10 in decidual T-cells, thereby contributing to a Th2 environment in first term placentas [36]. Furthermore, human pre-term placentas show increased levels of Th1 cytokines compared to term placentas, which express more Th2 cytokines [37]. Based on such data, it has been postulated that a shift from Th1 to Th2 cytokine profiles is required for a successful pregnancy [38], and that Th2 responses are more permissive for pregnancy.

However it is now becoming more and more evident that each trimester is associated with specific immunological needs. In particular, implantation and early pregnancy require a proinflammatory environment to allow for tissue remodeling that takes place during decidualisation. The blastocyst breaks through the epithelial lining of the uterus to implant, and placenta formation requires invasion of trophoblasts into the surrounding tissue [39]. Endometrial cells become specifically sensitive to IL1 family members, and produce pro-inflammatory and angiogenic factors [40]. Additionally, uNK and uDC cell activity in particular play a major role in vascularisation of the placenta, through their production of angiogenic factors such as TGF $\beta$ and vascular endothelial growth factor (VGEF) [41]. Furthermore, even though first trimester placentae are characterized by high IL-10 levels, IL-6, IL-8 and TNF $\alpha$ are also present or required for blastocyst implantation [42]. From first to second trimester, cellular populations in the uterus change, with total T-cell numbers increasing and macrophages and DC subsets decreasing as well as acquiring a tolerogenic phenotype [43]. Tolerance appears to be the predominant state throughout the main duration of pregnancy, but towards labor IL-10 levels decrease, and IL-6, TNF $\alpha$ and IL1 $\beta$ increase [44]. Thus, inflammatory processes are required for successful term labor and delivery, and immunological profiles may fluctuate during pregnancy (see Fig. 1).

\section{Immunology of pregnancy outside the uterus}

The general consensus thus far appears to be that implantation is associated low grade inflammation and a Th1 cytokine pattern, the main duration of pregnancy requires a shift towards toleranceassociated Th2 cytokines, while labor is initiated through Th1 cytokines at the uterus. To what extent these local immunological changes translate to peripheral effects is less clear. Case reports have suggested that pregnancy may reduce immunosuppressive therapy requirement in transplantation settings [45] and chronic inflammatory conditions such as inflammatory bowel disease [46]. In addition, disease course of several anti-immune diseases, including rheumatoid arthritis and multiple sclerosis were shown to be ameliorated during pregnancy [47-49], suggesting that this immune-tolerance goes beyond the placenta. It has indeed been proposed that pathological alterations in Th subsets occurring in utero during pregnancy failure are mirrored by peripheral alterations in these subsets [50]. However, studies investigating serum cytokine levels in healthy pregnancy over the three trimesters have been inconsistent. A recent study showed increased levels of both Treg cytokines (IL-10, sTNFRII) as well as Th1 cytokines (INF $\gamma$, IL-2, IL-12, IL-27) during the second trimester of pregnancy [51]. Two studies reported a decrease in TNF $\alpha$ from early to late pregnancy [52,53], although three other studies did not corroborate this finding [54-56] and one reported an increase of TNF $\alpha$ across the trimesters [57]. The most consisting finding to date appears to be increasing levels of IL6 (often considered a Th1 cytokine) from early to late pregnancy $[53-55,58,59]$. Similar controversy is seen for 
circulating immune cells. A recent study showed that peripheral blood subsets of $\mathrm{NK}$ cells and $\mathrm{CD} 4^{+} \mathrm{T}$-cells increased during pregnancy, while monocyte and $\mathrm{CD}^{+}{ }^{+} \mathrm{T}$ cell numbers remained stable over the trimesters, and peripheral Treg numbers decreased from upon conception [60]. However, others found no peripheral blood changes of $\mathrm{CD}^{+}$cells, and increased peripheral Treg populations during healthy pregnancy [61]. Despite these controversies, it has been demonstrated that peripheral immune cells from pregnant women react differently to external stimuli as compared to heathy controls: less cytokines of either the Th1 or the Th2 variant are produced when isolated blood cells from women in their second trimester are challenged with phorbol 12-myristate 13-acetate and ionomycin (a general, non-receptor stimulant), suggesting that a peripheral immune dampening effects of pregnancy may be present.

\section{Infectious diseases during pregnancy}

In addition to providing fetal tolerance, immunological changes occurring during pregnancy might be also expected to affect the way pathogenic threats are handled during this time. Recognition of pathogens by the adaptive immune system depends on presentation of their antigens on MHC-I molecules of infected cells (mostly in the case of viruses) or presentation of ingested microbes by MHC-II on APCs (mostly for bacteria) [62]. Furthermore, as mentioned above, viral and intracellular pathogens are generally associated with the development of a Th1 immune response. Thus, with the immunological changes taking place during pregnancy, it might be expected that pregnant women are more susceptible to infection with bacteria and viruses. Clinical and epidemiological evidence suggests that while pregnant women are not completely defenseless against pathogens [63], an increased susceptibility to some infectious diseases is indeed present [64]. Already in the 50's it was noted that pregnant women may be more susceptible to malaria-causing parasites. Seroconversion to toxoplasmosis gondii (a parasite transferred in food and sometimes spread via cats) is increased during pregnancy [65]. Viral infections also appear to be more common or more severe in pregnancy, as has been demonstrated for measles virus, influenza A virus, Hepatitis E virus and herpes simplex virus [66]. Nevertheless, seroconversion rates in response to influenza vaccines appear to be similar for pregnant and non-pregnant women, and are not affected gestational time during vaccination $[67,68]$. With regards to bacterial agents, it has been suggested that pregnancy either increases susceptibility to, or allows re-activation of latent infections, of the gastric bacterium Helicobacter pylori, which is linked to gastric ulcers and gastric cancer [69]. Furthermore, pregnant women are 17 times more likely to be affected by the foodborne Gramm positive bacterium Listeria monocytogenes, which can cause premature delivery, miscarriage and stillbirth [44]. Thus, while for the most part, systemic immunity towards most pathogens appears to be functional in pregnancy, in particular severity of disease upon contraction of some infectious agents is increased in pregnant women.

\section{Infections threatening the placenta/fetus}

One of the most common threats to healthy pregnancy is infection of the placenta or fetus with microbial, viral, protozoal or fungal agents. It is still debated whether the healthy placenta contains a bacterial microbiota. While some studies have shown the presence of bacteria at the maternal side of the placenta $[70,71]$, other studies were unable to find evidence of a unique placenta microbiome [72,73]. The presence of bacteria at the fetal side of the placental circulation has also been observed, with amniotic fluid described to contain Proteobacteria such as Enterobacter and
Escherichia/Shigella [74], but again, others were unable to replicate these findings [75,76]. Thus, controversy surrounds the presence of bacteria in the healthy placenta and with low bacterial abundant tissues prone to contamination and sequencing artifacts, studies should be interpreted with care. It may be that bacterial presence in the placenta is relevant only in pathological situations. Microbial contaminants seen in infected membranes include the genera Fusobacterium, Streptococcus, Mycoplasma, Aerococcus, Garderella and Ureaplasma and the family Enterobacteriaceae [77], with Ureaplasma urealyticum and Mycoplasma hominus presenting as the most common causes of infection [78]. Several bacteria seen in chorioamnionitis, including Bacteroides spp, Group B Streptococcus, Staphylococcus, E. coli and Klebsiella are also seen at low abundance in the healthy vaginal microbiota, consistent with ascending infections [79]. Interestingly, pregnancy hormones may modulate these vaginal bacteria, as demonstrated by decreased rates of Group B Streptococcus in patients taking progesterone for the prevention of preterm birth [80]. Furthermore, a lower prevalence of Ureaplasma and Mycoplasma was seen during pregnancy [81]. Pregnancy is associated with a reduced vaginal bacterial richness and diversity and a higher abundance of Lactobaccillus spp [82], both signs of a healthy vaginal microbiome and associated with improved fertility rates. Thus, it appears that pregnancy hormones may modulate the vaginal microbiome to reduce pathogen-derived risk to the fetus.

\section{Intestinal pathogenic threat to the fetus}

In addition to ascending bacterial infections which are characterized by the spread of vaginal/cervical pathogens to the uterus, hematogenous spread of blood borne pathogens from maternal to fetal circulation poses a second threat [83] (see Fig. 1B). Several food contaminants are known to be able to infect the placenta to detrimental effects, including Listeria, Salmonella, Brucella and Campylobacter [84-87]. Generally, these bacteria are prevented from reaching the blood stream by the epithelial lining of the gastrointestinal tract and its antimicrobial products (e.g. defensins and mucins). However, some bacteria, like Listeria, are able to invade and spread via epithelial and immune cells and may thereby enter the circulation [44]. Additionally, microbial composition, medications, dietary peptides, infiltrating immune cells, and cellular stress may all modulate the strength of the epithelial barrier and affect bacterial translocation.

Several mechanisms are in place to ensure limited damage from these food borne pathogens. Pregnancy hormones such as progesterone and estrogen directly enhance barrier function in in vitro model systems [88], which is supported by data in animal models [89]. Pathogens and their products which do manage to cross the feto-maternal interface in the placenta are there recognized by specialized pattern recognition receptors. Uterine epithelial cells express several of these toll like receptors (TLR), microbial peptide recognizing transmembrane molecules which play a role in innate immunity. Ligation of these receptors on human uterine epithelial cells induces the release of the chemokine IL-8 as well as monocyte chemotactic protein-1 (MCP1), which ensures the recruitment of phagocytes to eliminate bacterial threats [90]. On the other hand, TLR3 ligation on endometrial cells increases the production of IDO1 in the uterus [91], which has several anti-inflammatory properties, including the stimulation of Treg differentiation. In mice the expression of several TLRs are increased during pregnancy [92], and their expression is further enhanced by maternal viral infection [93]. While some level of TLR is required to maintain a defense against biological agents, too much inflammation can also be harmful in pregnancy. A reduced presence of the lipopolysaccharide receptor TLR4 on villous trophoblasts and decidua is associated 
with spontaneous abortion [94], but enhanced syncytium TLR4 levels were shown in patients with preeclampsia [95]. Additionally, TLR expression and functionality may depend on gestational stage, as at least in peripheral blood, TLR4 stimulated cytokine production is only increased in the first and third trimester of pregnancy [96]. Thus, inflammatory and anti-inflammatory processes need to be carefully balanced in order to eliminate potential pathogenic threats while maintaining a healthy pregnancy.

\section{Other interactions between the gut microbiome and pregnancy}

While microbes may occasionally pose a pathogenic threat, the human body hosts over $10^{13}$ bacteria, in what is generally a mutually beneficial symbiosis [97]. Most of these microbes reside in the gastrointestinal tract, where they are now being recognized as a vital part of the human metaorganism [98]. Animal studies have shown the importance of the intestinal microbiome for shaping local and peripheral immunity [99,100]. Bacteria are essential for the efficient metabolisation of indigestible fibers and production of vitamins $\mathrm{K}$ and $\mathrm{B}$. Metabolites produced by intestinal bacteria include short chain fatty acids (SCFA), of which butyrate and proprionate are a nutrient source for colonocytes and perform functions in gluconeogenesis, while acetate is a growth factor for other bacteria and plays a role in cholesterol metabolism [101].

With the recognition of the intestinal microbiota as important player in homeostasis, its potential role in metabolic disease is now also emerging. Early studies studying the microbiota in obese mice and humans pointed towards decreased ratio of Bacteroidetes/Firmicutes and reduced microbial diversity [102-104]. Subsequent studies and re-analyses of these data have challenged the importance of this ratio in obesity, leaving the exact microbial changes open [105,106]. Nevertheless, while the exact signature of the microbiota for obese individuals is unclear, obese and lean individuals can be accurately classified by their microbiomes [107], consistent with the fact that transplantation of fecal microbiota from obese individuals to lean mice can cause metabolic changes and weight gain in these mice [108]. The microbiome in patients with metabolic syndromes shows reduced levels of Bacteroides species and butyrate producing Faecalibacterium [109]. Furthermore, the microbiome in patients with type 2 diabetes (T2D) is altered, and modulation of thereof by Akkermansia municiphila administration, fecal transplants or the use of antibiotics can restore insulin sensitivity [110-112].

During pregnancy, insulin sensitivity fluctuates over time, to accommodate the changes in energy demand that accompany different phases of pregnancy. Early in pregnancy, insulin sensitivity is enhanced to allow establishment of fat stores for later energy demands, while at third trimester insulin sensitivity decreases and endogenous glucose production rises [113]. Interestingly, while the intestinal microbiome early in healthy pregnancy resembles that of non-pregnant women, late pregnancy is accompanied by reduced microbial diversity and reduced levels of Faecalibacterium $[53,114,115]$. Transfer of third trimester fecal bacteria to germ free mice resulted in increased weight gain, development of insulin resistance and inflammatory responses in these mice [116]. These data suggest that microbial alterations occurring during late pregnancy contribute to the physiological metabolic processes required in pregnancy. In up to $10 \%$ of women, insulin sensitivity drops to a point where they develop gestational diabetes mellitus (GDM) [117], which generally normalizes post-partum, but can nevertheless pose severe long-term health risks for mother and child. Obesity in pregnant women was also associated with specific microbial alterations, and weight gain in pregnancy has been correlated with increased Bacteroides levels [118] and reduced
Firmicutes [119] dominance mid-pregnancy. GDM was associated with increased rather than decreased levels of alpha diversity from middle to late pregnancy, with increased Firmicutes and Faecalibacterium and reduced Bacteroides [120]. Thus, pregnancy induces microbial changes corresponding to metabolic syndrome, but metabolic syndrome development in pregnancy does not appear to be a simple exaggeration of these microbial alterations.

\section{Microbial changes as cause or consequence of metabolic alterations in pregnancy}

Although some studies did not observe any microbial changes over time during gestation [121], a consistent finding in most studies appears to be a reduced diversity in microbial composition $[114,116,122,123]$. This begs the question as to how this process is regulated. One obvious answer would be that dietary changes during pregnancy may affect the microbiome. Consciously or subconsciously, pregnant women take in less alcohol, meat and caffeine, while intake of milk products, fruits and sweets increases [124]. In mice, periconceptional diet was shown to influence microbial changes taking place during pregnancy [125]. It is also conceivable that changes in diet work in concert with molecular changes occurring during pregnancy. As described previously, pregnancy increases levels of the enzyme IDO1, which catalyses the degradation of Trp, an essential amino-acid derived from diet, to kynurenin. Trp is also degraded by the intestinal microbiome to form beneficial indole metabolites which drive IL22 production and increase insulin sensitivity. In mice, it has been demonstrated that high fat diet induces IDO1 expression, which in turn skews Trp metabolism from microbial-related indole production to IDO-1mediated kynurenine production, and a decreased insulin sensitivity [126]. Although IDO1 levels in the gut and adipose tissues have not been directly studied in pregnancy, serum levels of kynurenine increase during pregnancy, suggesting increased systemic effects of IDO1 activity and increased IDO1 levels have been associated with metabolic disease [127]. Interestingly, the microbiome itself is also dependent on host IDO1 levels, demonstrating a reciprocal relationship between host and microbiome [126].

As mentioned earlier, there is also a reciprocal relationship between the microbiome and host immunity. Microbes play an important role in shaping the host immune response, and intestinal dysbiosis is a contributing factor to immunological disorders such as inflammatory bowel disease (IBD) and lupus erythematosus $[89,128,129]$. A loss of butyrate producing bacteria is associated with intestinal inflammation by increasing of IL17 levels and decreasing IL10 production and Treg generation [130]. Pregnancy improves inflammatory markers in patients with IBD, which is associated with microbial alterations and normalization of the microbiome in these patients [53]. While data on butyrate levels during human pregnancy is scarce, butyrate enhances embryo survival in rats when given during early pregnancy [131]. Conversely, immunological alterations also affect the microbial composition. For instance, overexpression of IL-15 in the intestinal epithelium drives microbiota changes associated with a decrease in butyrate producing bacteria and butyrate levels [132]. Enhanced (local) IL-15 levels have been associated with adverse pregnancy outcomes [133]. Thus, it is tempting to speculate that immunological alterations occurring during pregnancy also contribute to reshaping of the microbiome in pregnancy.

Pregnancy hormones may play a role in the reciprocal interaction between immunity and microbiome. Indeed, in vitro studies indicate that progesterone reduces bacterial richness but stimulates Faecalibacterium, Bacteroides and Bifidobacterium growth, amongst others [134]. Animal studies have shown that administration of exogenous estrogens at pregnancy levels alter the fecal 
microbiome in rats [135]. In this study, estrogen also protected against autoimmune encephalomyelitis-induced changes of microbiome, as well as development of EAE symptoms. These authors further showed that estrogen treatment was associated with mucosal expansion of regulatory B-cells and M2 macrophages, demonstrating a local protective effect and suggesting that estrogen may cause enrichment of bacteria with immune modulatory function. Furthermore, both progesterone and estrogen strengthen epithelial barrier function, which in turn may also affect bacterial composition [88]. Vice versa, the microbiome itself may adjust the levels of sexhormones produced [136], adding a further layer of complexity.

\section{Conclusions}

While it is by now well accepted that pregnancy is accompanied by substantial hormonal, immunological and microbial alterations, the exact interactions and processes governing these changes remain elusive. Several challenges contribute to our lack of understanding. For one thing, much of our knowledge regarding the local changes in immunological and microbial patterns is derived from either mouse experiments, or from pathological pregnancies. However, mouse placentae are considerably different from human placentae, in both morphology and the presence of uNK cell receptors [137]. Furthermore, most of what we have gleaned from human placentae comes from the study of different pathological situations, as otherwise healthy placental tissue at different gestational time points are generally unavailable. Secondly, it is becoming clear that like hormone levels, changes in immunological and microbial patterns fluctuate during pregnancy, and no longitudinal samples have ever been taken from healthy human placentae. Third, while local alterations associated with adverse pregnancy outcomes are to some extent correlated to peripheral immunological changes [50], there is remarkably little consensus as to the immunological changes taking place in the peripheral blood or other tissues during healthy pregnancy [89]. Similarly, studies investigating microbial changes occurring during pregnancy have not all been consistent. Technical differences between studies may account for the fact that not all studies show similar changes in immunological and (vaginal, intestinal, oral) microbial parameters, but that these parameters do change is not disputed [115]. The most consistent immunological and microbial findings include an increase in IL-6 cytokine levels and a decreased intestinal microbial diversity towards the third trimester. Cause and consequence of immunological and microbial alterations in pregnancy are difficult to distinguish. While pregnancy hormones can directly alter immunological responses as well as (intestinal) microbiomes [134], reciprocal interactions are present between the microbiome and immunity which may reinforce fluctuations in both. Thus, the concept of microbiome relating to our health as part of a metaorganism appears to extrapolate to the state of pregnancy.

Thus far, what is clear is that in general, tolerance against an MHC-mismatched fetus predominates in pregnancy, and that an altered susceptibility or response to certain viral or bacterial infections may exist. To what extent pregnancy improves of worsens (auto)inflammatory responses remains debated, and may depend on the disease and time point in pregnancy. Significant reduction of pro-inflammatory cytokine levels during pregnancy has been observed for patients with inflammatory bowel disease [53]. Similarly, pre-pregnancy differences in bacterial diversity normalized during pregnancy in these patients. A similar beneficial effect of pregnancy on disease activity was seen for rheumatoid arthritis, although increased flaring post-pregnancy may occur [49]. While a role for the intestinal microbiome was shown for lupus erythematosus, amelioration of disease by antibiotics treatment was seen for non-pregnant animals, but not for post-partum pregnant animals [138]. While these latter data also indicate that pregnancy alters the host-microbial interactions, in this case pregnancy was not beneficial. Similarly, microbiome alterations are seen in patients with multiple sclerosis [139], yet pregnancy worsens postpregnancy disease course in these patients [140]. Thus, some immunological diseases may be affected favorably during pregnancy, but post-partum flaring of disease is an imminent risk. Thus, special care should be taken both during pregnancy and postpartum regarding infectious diseases and inflammatory disorders. Overall, expanding our knowledge regarding the interactions between host and microbiome and the time-sensitive modulation thereof by hormones during pregnancy would perhaps allow a better identification of patients at risk of complications of either their pregnancy or concomitant diseases.

\section{Practice points}

- Immunological changes are seen during pregnancy, which may extend beyond the placenta

- Tolerance against fetal antigens during pregnancy does not mean a reduced immunological reactivity per se.

- Microbial alterations during pregnancy can have both pathogenic and protective effects

- Hormonal, immunological and microbial alterations taking place during pregnancy may alter susceptibility of pregnant women to infection and inflammatory disease.

- Pregnant patients should be carefully monitored for infectious disease and inflammatory disorders, both during pregnancy and post-partum

\section{Research agenda}

- Longitudinal changes in peripheral immune responses and microbiome alterations should be better defined.

- Identifying women at risk for pregnancy complications including GDM or pre-term birth could be improved by studying the interaction between host and microbiome

\section{References}

[1] Korevaar TIM, Steegers EAP, de Rijke YB, Schalekamp-Timmermans S, Visser WE, Hofman A, et al. Reference ranges and determinants of total hCG levels during pregnancy: the Generation R Study. Eur J Epidemiol 2015;30: 1057-66. https://doi.org/10.1007/s10654-015-0039-0.

[2] Cole LA. Biological functions of hCG and hCG-related molecules. Reprod Biol Endocrinol 2010;8:102. https://doi.org/10.1186/1477-7827-8-102.

[3] Sykes L, Bennett PR. Efficacy of progesterone for prevention of preterm birth. Best Pract Res Clin Obstet Gynaecol 2018;52:126-36. https://doi.org/ 10.1016/J.BPOBGYN.2018.08.006.

[4] Byrns MC. Regulation of progesterone signaling during pregnancy: implications for the use of progestins for the prevention of preterm birth. J Steroid Biochem Mol Biol 2014;139:173-81. https://doi.org/10.1016/ J.JSBMB.2013.01.015.

[5] Ravanos K, Dagklis T, Petousis S, Margioula-Siarkou C, Prapas Y, Prapas N. Factors implicated in the initiation of human parturition in term and preterm labor: a review. Gynecol Endocrinol 2015;31:679-83. https://doi.org/ 10.3109/09513590.2015.1076783.

[6] Albrecht ED, Pepe GJ. Estrogen regulation of placental angiogenesis and fetal ovarian development during primate pregnancy. Int J Dev Biol 2010;54: 397-408. https://doi.org/10.1387/ijdb.082758ea.

[7] PEPE GJ, ALBRECHT ED. Actions of placental and fetal adrenal steroid hormones in primate pregnancy*. Endocr Rev 1995;16:608-48. https://doi.org/ 10.1210/edrv-16-5-608.

[8] DESAI RG, CREGER WP. Maternofetal passage of leukocytes and platelets in man. Blood 1963;21:665-73.

[9] Iverson GM, Bianchi DW, Cann HM, Herzenberg LA. Detection and isolation of fetal cells from maternal blood using the fluorescence-activated cell sorter (FACS). Prenat Diagn 1981;1:61-73.

[10] Egbor M, Knott P, Bhide A. Red-cell and platelet alloimmunisation in pregnancy. Best Pract Res Clin Obstet Gynaecol 2012;26:119-32. https://doi.org/ 
10.1016/J.BPOBGYN.2011.10.004

[11] BILLINGHAM RE, BRENT L, MEDAWAR PB. 'Actively acquired tolerance' of foreign cells. Nature 1953;172:603-6. https://doi.org/10.1038/172603a0.

[12] Ingulli E. Mechanism of cellular rejection in transplantation. Pediatr Nephrol 2010;25:61-74. https://doi.org/10.1007/s00467-008-1020-x.

[13] Alegre M-L, Lakkis FG, Morelli AE. Antigen presentation in transplantation recognition of allografts: the basics. Trends Immunol 2016;37:831-43. https://doi.org/10.1016/j.it.2016.09.003.

[14] Sentman CL, Meadows SK, Wira CR, Eriksson M. Recruitment of uterine NK cells: induction of CXC chemokine ligands 10 and 11 in human endometrium by estradiol and progesterone. J Immunol 2004;173:6760-6. https://doi.org/ 10.4049/jimmunol.173.11.6760.

[15] Benichou G, Yamada Y, Aoyama A, Madsen JC. Natural killer cells in rejection and tolerance of solid organ allografts. Curr Opin Organ Transplant 2011;16: 47-53. https://doi.org/10.1097/MOT.0b013e32834254cf.

[16] Faas MM, de Vos P. Uterine NK cells and macrophages in pregnancy. Placenta 2017;56:44-52. https://doi.org/10.1016/J.PLACENTA.2017.03.001.

[17] Ishitani A, Sageshima N, Lee N, Dorofeeva N, Hatake K, Marquardt H, et al. Protein expression and peptide binding suggest unique and interacting functional roles for HLA-E, F, and G in maternal-placental immune recognition. J Immunol 2003;171:1376-84. https://doi.org/10.4049/ jimmunol.171.3.1376.

[18] Guleria I, Sayegh MH. Maternal acceptance of the fetus: True human tolerance. J Immunol 2007;178:3345-51. https://doi.org/10.4049/ JIMMUNOL.178.6.3345.

[19] Rogers AM, Boime I, Connolly J, Cook JR, Russell JH. Maternal-fetal tolerance is maintained despite transgene-driven trophoblast expression of MHC class I, and defects in Fas and its ligand. Eur J Immunol 1998;28:3479-87. https:// doi.org/10.1002/(SICI)1521-4141(199811)28:11<3479::AID IMMU3479>3.0.CO;2-U.

[20] Powell RM, Lissauer D, Tamblyn J, Beggs A, Cox P, Moss P, et al. Decidual T cells exhibit a highly differentiated phenotype and demonstrate potential fetal specificity and a strong transcriptional response to IFN. J Immunol 2017;199:3406-17. https://doi.org/10.4049/jimmunol.1700114.

[21] Petroff MG. Review: fetal antigens-identity, origins, and influences on the maternal immune system. Placenta 2011;32(Suppl 2):S176-81. https:// doi.org/10.1016/j.placenta.2010.12.014.

[22] Erlebacher A, Vencato D, Price KA, Zhang D, Glimcher LH. Constraints in antigen presentation severely restrict $\mathrm{T}$ cell recognition of the allogeneic fetus. J Clin Invest 2007;117:1399-411. https://doi.org/10.1172/JCI28214.

[23] Erlebacher A. Immune surveillance of the maternal/fetal interface: controversies and implications n.d. https://doi.org/10.1016/j.tem.2010.02.003; 2010.

[24] Collins MK, Tay C-S, Erlebacher A. Dendritic cell entrapment within the pregnant uterus inhibits immune surveillance of the maternal/fetal interface in mice. J Clin Invest 2009;119:2062-73. https://doi.org/10.1172/JCI38714.

[25] Sauss K, Ehrentraut S, Zenclussen AC, Schumacher A. The pregnancy hormone human chorionic gonadotropin differentially regulates plasmacytoid and myeloid blood dendritic cell subsets. Am J Reprod Immunol 2018: e12837. https://doi.org/10.1111/aji.12837.

[26] Tafuri A, Alferink J, ller P M, H mmerling GnJ, Arnold BT. Cell awareness of paternal alloantigens during pregnancy. Science 1995;270:630-3. https:// doi.org/10.1126/science.270.5236.630. 80-.

[27] Levings MK, Bacchetta R, Schulz U, Roncarolo MG. The role of IL-10 and TGF$\beta$ in the differentiation and effector function of T regulatory cells. Int Arch Allergy Immunol 2002;129:263-76. https://doi.org/10.1159/000067596.

[28] Aluvihare VR, Kallikourdis M, Betz AG. Regulatory T cells mediate maternal tolerance to the fetus. Nat Immunol 2004;5:266-71. https://doi.org/ 10.1038/ni1037.

[29] Tilburgs T, Roelen DL, van der Mast BJ, de Groot-Swings GM, Kleijburg C, Scherjon SA, et al. Evidence for a selective migration of fetus-specific CD4 CD25 bright regulatory T cells from the peripheral blood to the decidua in human pregnancy. J Immunol 2008;180:5737-45. https://doi.org/10.4049/ jimmunol.180.8.5737.

[30] Svensson-Arvelund J, Mehta RB, Lindau R, Mirrasekhian E, Rodriguez Martinez $\mathrm{H}$, Berg $\mathrm{G}$, et al. The human fetal placenta promotes tolerance against the semiallogeneic fetus by inducing regulatory $\mathrm{T}$ cells and homeostatic M2 macrophages. J Immunol 2015;194:1534-44. https://doi.org/ 10.4049/jimmunol.1401536.

[31] Svensson-Arvelund J, Ernerudh J. The role of macrophages in promoting and maintaining homeostasis at the fetal-maternal interface. Am J Reprod Immunol 2015;74:100-9. https://doi.org/10.1111/aji.12357.

[32] Munn DH, Mellor AL. Indoleamine 2,3 dioxygenase and metabolic control of immune responses. Trends Immunol 2013;34:137-43. https://doi.org/ 10.1016/j.it.2012.10.001.

[33] Mondanelli G, Bianchi R, Pallotta MT, Orabona C, Albini E, Iacono A, et al. A relay pathway between arginine and tryptophan metabolism confers immunosuppressive properties on dendritic cells. Immunity 2017;46: 233-44. https://doi.org/10.1016/j.immuni.2017.01.005.

[34] Mosmann TR, Cherwinski H, Bond MW, Giedlin MA, Coffman RL. Two types of murine helper T cell clone. I. Definition according to profiles of lymphokine activities and secreted proteins. J Immunol 1986;136:2348-57.

[35] Brucklacher-Waldert V, Carr EJ, Linterman MA, Veldhoen M. Cellular plasticity of CD4+ T cells in the intestine. Front Immunol 2014;5:488. https:// doi.org/10.3389/fimmu.2014.00488.
[36] Zhang Y, Wang Y, Li M-Q Duan J, Fan D-X, Jin L-P. IL-25 promotes Th2 bias by upregulating IL-4 and IL-10 expression of decidual $\gamma \delta \mathrm{T}$ cells in early pregnancy. Exp Ther Med 2018;15:1855-62. https://doi.org/10.3892/ etm.2017.5638.

[37] El-Shazly S, Makhseed M, Azizieh F, Raghupathy R. Increased expression of pro-inflammatory cytokines in placentas of women undergoing spontaneous preterm delivery or premature rupture of membranes. Am J Reprod Immunol 2004;52:45-52. https://doi.org/10.1111/j.1600-0897.2004.00181.x.

[38] Sykes L, MacIntyre DA, Yap XJ, Teoh TG, Bennett PR. The Th1:th2 dichotomy of pregnancy and preterm labour. Mediat Inflamm 2012;2012:967629. https://doi.org/10.1155/2012/967629.

[39] Moser G, Windsperger K, Pollheimer J, de Sousa Lopes SC, Huppertz B. Human trophoblast invasion: new and unexpected routes and functions. Histochem Cell Biol 2018;150:361-70. https://doi.org/10.1007/s00418-0181699-0.

[40] Bourdiec A, Ahmad S-F, Lachhab A, Akoum A. Regulation of inflammatory and angiogenesis mediators in a functional model of decidualized endometrial stromal cells. Reprod Biomed Online 2016;32:85-95. https://doi.org/ 10.1016/j.rbmo.2015.09.011.

[41] Plaks V, Birnberg T, Berkutzki T, Sela S, BenYashar A, Kalchenko V, et al. Uterine DCs are crucial for decidua formation during embryo implantation in mice. J Clin Invest 2008;118:3954-65. https://doi.org/10.1172/JCI36682.

[42] Caballero-Campo P, Domínguez F, Coloma J, Meseguer M, Remohí J, Pellicer A, et al. Hormonal and embryonic regulation of chemokines IL-8, MCP-1 and RANTES in the human endometrium during the window of implantation. Mol Hum Reprod 2002;8:375-84. https://doi.org/10.1093/ molehr/8.4.375.

[43] Kwan M, Hazan A, Zhang J, Jones RL, Harris LK, Whittle W, et al. Dynamic changes in maternal decidual leukocyte populations from first to second trimester gestation. Placenta 2014;35:1027-34. https://doi.org/10.1016/ j.placenta.2014.09.018.

[44] Pohl AM, Pouillot R, Bazaco MC, Wolpert BJ, Healy JM, Bruce BB, et al. Differences among incidence rates of invasive listeriosis in the U.S. FoodNet population by age, sex, race/ethnicity, and pregnancy status, 2008-2016. Foodb Pathog Dis 2019;16:290-7. https://doi.org/10.1089/fpd.2018.2548.

[45] Fischer T, Schobel H, Barenbrock M. Specific immune tolerance during pregnancy after renal transplantation. Eur J Obstet Gynecol Reprod Biol 1996;70:217-9. https://doi.org/10.1016/s0301-2115(95)02581-2.

[46] de Lima A, Zelinkova Z, van der Ent C, Steegers EAP, van der Woude CJ. Tailored anti-TNF therapy during pregnancy in patients with IBD: maternal and fetal safety. Gut 2016;65:1261-8. https://doi.org/10.1136/gutjnl-2015309321.

[47] Ysrraelit MC, Correale J. Impact of sex hormones on immune function and multiple sclerosis development. Immunology 2019;156:9-22. https:// doi.org/10.1111/imm.13004.

[48] Barrett JH, Brennan P, Fiddler M, Silman AJ. Does rheumatoid arthritis remit during pregnancy and relapse postpartum?: results from a nationwide study in the United Kingdom performed prospectively from late pregnancy. Arthritis Rheum 1999;42:1219-27. https://doi.org/10.1002/15290131(199906)42:6<1219::AID-ANR19>3.0.CO;2-G.

[49] de Man YA, Dolhain RJEM, van de Geijn FE, Willemsen SP, Hazes JMW. Disease activity of rheumatoid arthritis during pregnancy: results from a nationwide prospective study. Arthritis Rheum 2008;59:1241-8. https:// doi.org/10.1002/art.24003.

[50] Saito S, Nakashima A, Shima T, Ito M. Th1/Th2/Th17 and regulatory T-cell paradigm in pregnancy. Am J Reprod Immunol 2010;63:601-10. https:// doi.org/10.1111/j.1600-0897.2010.00852.x.

[51] Tagoma A, Haller-Kikkatalo K, Roos K, Oras A, Kirss A, Ilonen J, et al. Interleukin-7, $\mathrm{T}$ helper 1 and regulatory $\mathrm{T}$-cell activity-related cytokines are increased during the second trimester of healthy pregnancy compared to non-pregnant women. Am J Reprod Immunol 2019:1-10. https://doi.org/ 10.1111/aji.13188. aji.13188.

[52] Doria A, Cutolo M, Ghirardello A, Zen M, Villalta D, Tincani A, et al. Effect of pregnancy on serum cytokines in SLE patients. Arthritis Res Ther 2012;14: R66. https://doi.org/10.1186/ar3782.

[53] van der Giessen J, Binyamin D, Belogolovski A, Frishman S, TenenbaumGavish K, Hadar E, et al. Modulation of cytokine patterns and microbiome during pregnancy in IBD. Gut 2020;69(3):473-86. https://doi.org/10.1136/ gutjnl-2019-318263. gutjnl-2019-318263.

[54] Vassiliadis S, Ranella A, Papadimitriou L, Makrygiannakis A, Athanassakis I. Serum levels of pro- and anti-inflammatory cytokines in non-pregnant women, during pregnancy, labour and abortion. Mediat Inflamm 1998;7: 69-72. https://doi.org/10.1080/09629359891199.

[55] Christian LM, Porter K. Longitudinal changes in serum proinflammatory markers across pregnancy and postpartum: effects of maternal body mass index. Cytokine 2014;70:134-40. https://doi.org/10.1016/ j.cyto.2014.06.018.

[56] Martínez-Varea A, Pellicer B, Serra V, Hervás-Marín D, Martínez-Romero A, Bellver J, et al. The maternal cytokine and chemokine profile of naturally conceived gestations is mainly preserved during in vitro fertilization and egg donation pregnancies. J Immunol Res 2015;2015. https://doi.org/10.1155/ 2015/128616.

[57] Ashford K, Chavan N, Wiggins A, Sayre M, McCubbin A, Critchfield A, et al Comparison of serum and cervical cytokine levels throughout pregnancy between preterm and term births. Am J Perinatol Reports 2018;08:e113-20. 
https://doi.org/10.1055/s-0038-1656534.

[58] Coussons-Read ME, Okun ML, Nettles CD. Psychosocial stress increases inflammatory markers and alters cytokine production across pregnancy. Brain Behav Immun 2007;21:343-50. https://doi.org/10.1016/j.bbi.2006.08.006.

[59] Doria A, Ghirardello A, Iaccarino L, Zampieri S, Punzi L, Tarricone E, et al. Pregnancy, cytokines, and disease activity in systemic lupus erythematosus. Arthritis Care Res (Hoboken) 2004;51:989-95. https://doi.org/10.1002/ art.20837.

[60] Spadaro M, Martire S, Marozio L, Mastromauro D, Montanari E, Perga S, et al. Immunomodulatory effect of pregnancy on leukocyte populations in patients with multiple sclerosis: a comparison of peripheral blood and decidual placental tissue. Front Immunol 2019;10:1935. https://doi.org/10.3389/ fimmu.2019.01935.

[61] Qian J, Zhang N, Lin J, Wang C, Pan X, Chen L, et al. Distinct pattern of Th17/ Treg cells in pregnant women with a history of unexplained recurrent spontaneous abortion. Biosci Trends 2018;12:157-67. https://doi.org/ 10.5582 /bst.2018.01012.

[62] Kobayashi KS, van den Elsen PJ. NLRC5: a key regulator of MHC class Idependent immune responses. Nat Rev Immunol 2012;12:813-20. https:/ doi.org/10.1038/nri3339.

[63] Racicot K, Kwon J-Y, Aldo P, Silasi M, Mor G. Understanding the complexity of the immune system during pregnancy. Am J Reprod Immunol 2014;72: 107-16. https://doi.org/10.1111/aji.12289.

[64] Jamieson DJ, Theiler RN, Rasmussen SA. Emerging infections and pregnancy. Emerg Infect Dis 2006;12:1638-43. https://doi.org/10.3201/ eid1211.060152.

[65] Avelino MM, Campos D, do Carmo Barbosa de Parada J, de Castro AM. Medical School of the Federal University of Goiás, Institute of Tropical Pathology and Public Health of the Federal University of Goiás, et al. Pregnancy as a risk factor for acute toxoplasmosis seroconversion. Eur J Obstet Gynecol Reprod Biol 2003;108:19-24. https://doi.org/10.1016/s0301-2115(02) 00353-6.

[66] Sappenfield E, Jamieson DJ, Kourtis AP. Pregnancy and susceptibility to infectious diseases. Infect Dis Obstet Gynecol 2013;2013:752852. https:// doi.org/10.1155/2013/752852.

[67] Kay AW, Bayless NL, Fukuyama J, Aziz N, Dekker CL, Mackey S, et al. Pregnancy does not attenuate the antibody or plasmablast response to inactivated influenza vaccine. J Infect Dis 2015;212:861-70. https://doi.org/ 10.1093/infdis/jiv138.

[68] Dhakal S, Klein SL. Host factors impact vaccine efficacy: implications for seasonal and universal influenza vaccine programs. J Virol 2019;93. https:// doi.org/10.1128/jvi.00797-19.

[69] Cardaropoli S, Rolfo A, Todros T. Helicobacter pylori and pregnancy-related disorders. World J Gastroenterol 2014;20:654-64. https://doi.org/10.3748/ wjg.v20.i3.654.

[70] Stout MJ, Conlon B, Landeau M, Lee I, Bower C, Zhao Q et al. Identification of intracellular bacteria in the basal plate of the human placenta in term and preterm gestations. Am J Obstet Gynecol 2013;208. https://doi.org/10.1016/ j.ajog.2013.01.018. 226.e1-226.e7.

[71] Aagaard K, Ma J, Antony KM, Ganu R, Petrosino J, Versalovic J. The placenta harbors a unique microbiome. Sci Transl Med 2014;6:237ra65. https:// doi.org/10.1126/scitranslmed.3008599.

[72] Leiby JS, McCormick K, Sherrill-Mix S, Clarke EL, Kessler LR, Taylor LJ, et al. Lack of detection of a human placenta microbiome in samples from preterm and term deliveries. Microbiome 2018;6:196. https://doi.org/10.1186/ s40168-018-0575-4.

[73] Lauder AP, Roche AM, Sherrill-Mix S, Bailey A, Laughlin AL, Bittinger K, et al. Comparison of placenta samples with contamination controls does not provide evidence for a distinct placenta microbiota. Microbiome 2016;4:29. https://doi.org/10.1186/s40168-016-0172-3.

[74] Collado MC, Rautava S, Aakko J, Isolauri E, Salminen S. Human gut colonisation may be initiated in utero by distinct microbial communities in the placenta and amniotic fluid. Sci Rep 2016;6:23129. https://doi.org/10.1038/ srep23129.

[75] Perez-Muñoz ME, Arrieta M-C, Ramer-Tait AE, Walter JA. Critical assessment of the "sterile womb" and "in utero colonization" hypotheses: implications for research on the pioneer infant microbiome. Microbiome 2017;5:48. https://doi.org/10.1186/s40168-017-0268-4.

[76] Malmuthuge N, Griebel PJ. Fetal environment and fetal intestine are sterile during the third trimester of pregnancy. Vet Immunol Immunopathol 2018;204:59-64. https://doi.org/10.1016/J.VETIMM.2018.09.005.

[77] Doyle RM, Alber DG, Jones HE, Harris K, Fitzgerald F, Peebles D, et al. Term and preterm labour are associated with distinct microbial community structures in placental membranes which are independent of mode of delivery. Placenta 2014;35:1099-101. https://doi.org/10.1016 J.PLACENTA.2014.10.007.

[78] Goldenberg RL, McClure EM, Saleem S, Reddy UM. Infection - related stillbirths. Lancet 2010;375:1482. https://doi.org/10.1016/S0140-6736(09) 61712-8.

[79] Larsen B, Monif GRG. Understanding the bacterial flora of the female genital tract, vol. 32; 2001.

[80] Ma'ayeh M, Rood K, Walker H, Oliver E, Gee S, Iams J. Vaginal progesterone is associated with decreased Group B Streptococcus colonisation at term: retrospective cohort study. BJOG An Int J Obstet Gynaecol 2019;126(9): 1141-7. https://doi.org/10.1111/1471-0528.15801. 1471-0528.15801.
[81] Freitas AC, Chaban B, Bocking A, Rocco M, Yang S, Hill JE, et al. The vagina microbiome of pregnant women is less rich and diverse, with lower prevalence of Mollicutes, compared to non-pregnant women. Sci Rep 2017;7: 9212. https://doi.org/10.1038/s41598-017-07790-9.

[82] Aagaard K, Riehle K, Ma J, Segata N, Mistretta T-A, Coarfa C, et al. A metagenomic approach to characterization of the vaginal microbiome signature in pregnancy. PloS One 2012;7:e36466. https://doi.org/10.1371/ journal.pone.0036466.

[83] McClure EM, Dudley DJ, Reddy U, Goldenberg RL. Infectious causes of stillbirth: a clinical perspective. Clin Obstet Gynecol 2010;53:635. https:// doi.org/10.1097/GRF.0B013E3181EB6620.

[84] Delcourt C, Yombi JC, Vo B, Yildiz H. Salmonella enteritidis during pregnancy, a rare cause of septic abortion: case report and review of the literature. J Obstet Gynaecol (Lahore) 2019;39:554-5. https://doi.org/10.1080/ 01443615.2018.1529153.

[85] Kuperman-Shani A, Vaknin Z, Mendlovic S, Zaidenstein R, Melcer Y, Maymon R. Campylobacter coli infection causing second trimester intrauterine growth restriction (IUGR): a case report and review of the literature. Prenat Diagn 2015;35:1258-61. https://doi.org/10.1002/pd.4670.

[86] Khan MY, Mah MW, Memish ZA. Brucellosis in pregnant women. Clin Infect Dis 2001;32:1172-7. https://doi.org/10.1086/319758.

[87] Inan A, Erdem H, Elaldi N, Gulsun S, Karahocagil MK, Pekok AU, et al. Brucellosis in pregnancy: results of multicenter ID-IRI study. Eur J Clin Microbiol Infect Dis 2019;1-8. https://doi.org/10.1007/s10096-019-03540-z.

[88] van der Giessen J, van der Woude C, Peppelenbosch M, Fuhler G. A direct effect of sex hormones on epithelial barrier function in inflammatory bowel disease models. Cells 2019;8:261. https://doi.org/10.3390/cells8030261.

[89] van der Giessen J, Huang VW, van der Woude CJ, Fuhler GM. Modulatory effects of pregnancy on inflammatory bowel disease. Clin Transl Gastroenterol 2019;10:e00009. https://doi.org/10.14309/ctg.0000000000000009.

[90] Schaefer TM, Desouza K, Fahey JV, Beagley KW, Wira CR. Toll-like receptor (TLR) expression and TLR-mediated cytokine/chemokine production by human uterine epithelial cells. Immunology 2004;112:428-36. https://doi.org/ 10.1111/j.1365-2567.2004.01898.x.

[91] Wang B, Koga K, Osuga Y, Cardenas I, Izumi G, Takamura M, et al. Toll-like receptor-3 ligation-induced indoleamine 2, 3-dioxygenase expression in human trophoblasts. Endocrinology 2011;152:4984-92. https://doi.org/ 10.1210/en.2011-0278.

[92] Gonzalez JM, Xu H, Ofori E, Elovitz MA. Toll-like receptors in the uterus, cervix, and placenta: is pregnancy an immunosuppressed state? Am J Obstet Gynecol 2007;197. https://doi.org/10.1016/j.ajog.2007.06.021. 296.e1296.e6.

[93] Liao Y, Zhang Y, Liu X, Lu Y, Zhang L, Xi T, et al. Maternal murine cytomegalovirus infection during pregnancy up-regulates the gene expression of tolllike receptor 2 and 4 in placenta. Curr Med Sci 2018;38:632-9. https:/ doi.org/10.1007/s11596-018-1924-z.

[94] Kolben TM, Rogatsch E, Hester A, Kuhn C, Schmoeckel E, Czogalla B, et al. Involvement of ILR4 $\alpha$ and TLR4 in miscarriages. J Reprod Immunol 2019;131: 36-43. https://doi.org/10.1016/j.jri.2018.12.001.

[95] Tangerås LH, Silva GB, Stødle GS, Gierman LM, Skei B, Collett K, et al Placental inflammation by HMGB1 activation of TLR4 at the syncytium. Placenta 2018;72-73:53-61. https://doi.org/10.1016 j.placenta.2018.10.011.

[96] Ziegler SM, Feldmann CN, Hagen SH, Richert L, Barkhausen T, Goletzke J et al. Innate immune responses to toll-like receptor stimulation are altered during the course of pregnancy. J Reprod Immunol 2018;128:30-7. https:// doi.org/10.1016/J.JRI.2018.05.009.

[97] Sender R, Fuchs S, Milo R. Revised estimates for the number of human and bacteria cells in the body. PLoS Biol 2016;14:e1002533. https://doi.org 10.1371/journal.pbio.1002533.

[98] Turnbaugh PJ, Ley RE, Hamady M, Fraser-Liggett CM, Knight R, Gordon JI. The human microbiome project. Nature 2007;449:804-10. https://doi.org 10.1038 /nature06244.

[99] Grigg JB, Sonnenberg GF. Host-microbiota interactions shape local and systemic inflammatory diseases. J Immunol 2017;198:564-71. https://doi.org/ 10.4049/jimmunol.1601621.

[100] Round JL, Mazmanian SK. The gut microbiota shapes intestinal immune responses during health and disease. Nat Rev Immunol 2009;9:313-23. https://doi.org/10.1038/nri2515.

[101] Rowland I, Gibson G, Heinken A, Scott K, Swann J, Thiele I, et al. Gut microbiota functions: metabolism of nutrients and other food components. Eur J Nutr 2018;57:1-24. https://doi.org/10.1007/s00394-017-1445-8.

[102] Zhang H, DiBaise JK, Zuccolo A, Kudrna D, Braidotti M, Yu Y, et al. Human gut microbiota in obesity and after gastric bypass. Proc Natl Acad Sci U S A 2009;106:2365-70. https://doi.org/10.1073/pnas.0812600106.

[103] Turnbaugh PJ, Ley RE, Mahowald MA, Magrini V, Mardis ER, Gordon JI. An obesity-associated gut microbiome with increased capacity for energy harvest. Nature 2006;444:1027-31. https://doi.org/10.1038/nature05414.

104] David LA, Maurice CF, Carmody RN, Gootenberg DB, Button JE, Wolfe BE et al. Diet rapidly and reproducibly alters the human gut microbiome. Nature 2014;505:559-63. https://doi.org/10.1038/nature12820.

[105] Sze MA, Schloss PD, Fraser CM. Looking for a signal in the noise: revisiting obesity and the microbiome. https://doi.org/10.1128/mBio.01018-16; 2016.

[106] Finucane MM, Sharpton TJ, Laurent TJ, Pollard KS. A taxonomic signature of obesity in the microbiome? Getting to the guts of the matter. PloS One 
2014;9:e84689. https://doi.org/10.1371/journal.pone.0084689.

[107] Walters WA, Xu Z, Knight R. Meta-analyses of human gut microbes associated with obesity and IBD. FEBS Lett 2014;588:4223-33. https://doi.org/ 10.1016/j.febslet.2014.09.039.

[108] Ridaura VK, Faith JJ, Rey FE, Cheng J, Duncan AE, Kau AL, et al. Gut microbiota from twins discordant for obesity modulate metabolism in mice. 80- Science 2013;341. https://doi.org/10.1126/science.1241214. 1241214-1241214.

[109] Haro C, Garcia-Carpintero S, Alcala-Diaz JF, Gomez-Delgado F, DelgadoLista J, Perez-Martinez P, et al. The gut microbial community in metabolic syndrome patients is modified by diet. J Nutr Biochem 2016;27:27-31. https://doi.org/10.1016/j.jnutbio.2015.08.011.

[110] Vrieze A, Van Nood E, Holleman F, Salojärvi J, Kootte RS, Bartelsman JFWM et al. Transfer of intestinal microbiota from lean donors increases insulin sensitivity in individuals with metabolic syndrome. Gastroenterology 2012;143:913-6. https://doi.org/10.1053/j.gastro.2012.06.031. e7.

[111] Vrieze A, Out C, Fuentes S, Jonker L, Reuling I, Kootte RS, et al. Impact of ora vancomycin on gut microbiota, bile acid metabolism, and insulin sensitivity. J Hepatol 2014;60:824-31. https://doi.org/10.1016/j.jhep.2013.11.034.

[112] Everard A, Belzer C, Geurts L, Ouwerkerk JP, Druart C, Bindels LB, et al. Crosstalk between Akkermansia muciniphila and intestinal epithelium controls diet-induced obesity. Proc Natl Acad Sci 2013;110:9066-71. https://doi.org/ 10.1073/pnas.1219451110.

[113] Catalano PM. Trying to understand gestational diabetes. Diabet Med 2014;31:273-81. https://doi.org/10.1111/dme.12381.

[114] Torres J, Hu J, Seki A, Eisele C, Nair N, Huang R, et al. Infants born to mothers with IBD present with altered gut microbiome that transfers abnormalitie of the adaptive immune system to germ-free mice. Gut 2020;69(1):42-51. https://doi.org/10.1136/gutjnl-2018-317855. gutjnl-2018-317855.

[115] Nuriel-Ohayon M, Neuman H, Koren O. Microbial changes during pregnancy, birth, and infancy. Front Microbiol 2016;7:1031. https://doi.org/10.3389/ fmicb.2016.01031.

[116] Koren O, Goodrich JK, Cullender TC, Spor A, Laitinen K, Bäckhed HK, et al. Host remodeling of the gut microbiome and metabolic changes during pregnancy. Cell 2012;150:470-80. https://doi.org/10.1016 j.cell.2012.07.008

[117] Behboudi-Gandevani S, Amiri M, Bidhendi Yarandi R, Ramezani Tehrani F. The impact of diagnostic criteria for gestational diabetes on its prevalence: a systematic review and meta-analysis. Diabetol Metab Syndrome 2019;11:11 https://doi.org/10.1186/s13098-019-0406-1.

[118] Collado MC, Isolauri E, Laitinen K, Salminen S. Distinct composition of gut microbiota during pregnancy in overweight and normal-weight women. Am J Clin Nutr 2008;88:894-9. https://doi.org/10.1093/ajcn/88.4.894.

[119] Aatsinki AK, Uusitupa HM, Munukka E, Pesonen H, Rintala A, Pietilä S, et al. Gut microbiota composition in mid-pregnancy is associated with gestationa weight gain but not prepregnancy body mass index. J Wom Health 2018;27: 1293-301. https://doi.org/10.1089/jwh.2017.6488.

[120] Ferrocino I, Ponzo V, Gambino R, Zarovska A, Leone F, Monzeglio C, et al. Changes in the gut microbiota composition during pregnancy in patient with gestational diabetes mellitus (GDM). Sci Rep 2018;8:12216. https:// doi.org/10.1038/s41598-018-30735-9.

[121] DiGiulio DB, Callahan BJ, McMurdie PJ, Costello EK, Lyell DJ, Robaczewska A et al. Temporal and spatial variation of the human microbiota during pregnancy. Proc Natl Acad Sci 2015;112:11060-5. https://doi.org/10.1073/ pnas.1502875112.

[122] Rothenberg SE, Wagner CL, Hamidi B, Alekseyenko AV, Andrea AzcaratePeril M. Longitudinal changes during pregnancy in gut microbiota and methylmercury biomarkers, and reversal of microbe-exposure correlations. Environ $\quad$ Res 2019;172:700-12. https://doi.org/10.1016 j.envres.2019.01.014

[123] Khan I, Yasir M, Farman M, Kumosani T, AlBasri SF, Bajouh OS, et al. Evaluation of gut bacterial community composition and antimicrobial resistome in pregnant and non-pregnant women from Saudi population. Infect Drug Resist 2019;12:1749-61. https://doi.org/10.2147/IDR.S200213.
[124] Forbes LE, Graham JE, Berglund C, Bell RC. Dietary change during pregnancy and women's reasons for change. Nutrients 2018;10. https://doi.org/ $10.3390 /$ nu10081032

[125] Gohir W, Whelan FJ, Surette MG, Moore C, Schertzer JD, Sloboda DM. Pregnancy-related changes in the maternal gut microbiota are dependent upon the mother's periconceptional diet. Gut Microb 2015;6:310-20. https:// doi.org/10.1080/19490976.2015.1086056.

[126] Laurans L, Venteclef N, Haddad Y, Chajadine M, Alzaid F, Metghalchi S, et al. Genetic deficiency of indoleamine 2,3-dioxygenase promotes gut microbiota-mediated metabolic health. Nat Med 2018;24:1113-20. https:// doi.org/10.1038/s41591-018-0060-4.

[127] Schröcksnadel K, Widner B, Bergant A, Neurauter G, Schennach H, Schröcksnadel $\mathrm{H}$, et al. Longitudinal study of tryptophan degradation during and after pregnancy. Life Sci 2003;72:785-93. https://doi.org/10.1016/ s0024-3205(02)02304-4.

[128] Deuring JJ, Fuhler GM, Konstantinov SR, Peppelenbosch MP, Kuipers EJ, de Haar C, et al. Genomic ATG16L1 risk allele-restricted Paneth cell ER stress in quiescent Crohn's disease. Gut 2014;63:1081-91. https://doi.org/10.1136/ gutjnl-2012-303527.

[129] Eppinga H, Fuhler GM, Peppelenbosch MP, Hecht GA. Gut microbiota developments with emphasis on inflammatory bowel disease: report from the gut microbiota for health world summit. 2016 Gastroenterology 2016;151. https://doi.org/10.1053/j.gastro.2016.06.024.

[130] Zhang M, Zhou Q, Dorfman RG, Huang X, Fan T, Zhang H, et al. Butyrate inhibits interleukin-17 and generates Tregs to ameliorate colorectal colitis in rats. BMC Gastroenterol 2016;16:84. https://doi.org/10.1186/s12876-0160500-X.

[131] Ye Q, Cai S, Wang S, Zeng X, Ye C, Chen M, et al. Maternal short and medium chain fatty acids supply during early pregnancy improves embryo survival through enhancing progesterone synthesis in rats. J Nutr Biochem 2019;69: 98-107. https://doi.org/10.1016/j.jnutbio.2019.03.015.

[132] Meisel M, Mayassi T, Fehlner-Peach H, Koval JC, O’Brien SL, Hinterleitner R, et al. Interleukin-15 promotes intestinal dysbiosis with butyrate deficiency associated with increased susceptibility to colitis. ISME J 2017;11:15-30. https://doi.org/10.1038/ismej.2016.114.

[133] Daponte A, Deligeoroglou E, Pournaras S, Hadjichristodoulou C, Garas A, Anastasiadou F, et al. Interleukin-15 (IL-15) and anti-C1q antibodies as serum biomarkers for ectopic pregnancy and missed abortion. Clin Dev Immunol 2013;2013:637513. https://doi.org/10.1155/2013/637513.

[134] Nuriel-Ohayon M, Neuman H, Ziv O, Belogolovski A, Barsheshet Y, Bloch N, et al. Progesterone increases Bifidobacterium relative abundance during late pregnancy. Cell Rep 2019;27:730-6. https://doi.org/10.1016/j.celrep.2019.03.075. e3.

[135] Benedek G, Zhang J, Nguyen H, Kent G, Seifert HA, Davin S, et al. Estrogen protection against EAE modulates the microbiota and mucosal-associated regulatory cells. J Neuroimmunol 2017;310:51-9. https://doi.org/10.1016/ j.jneuroim.2017.06.007.

[136] Markle JGM, Frank DN, Mortin-Toth S, Robertson CE, Feazel LM, RolleKampczyk U, et al. Sex differences in the gut microbiome drive hormonedependent regulation of autoimmunity. Science 2013;339:1084-8. https:// doi.org/10.1126/science.1233521. 80-.

[137] Ander SE, Diamond MS, Coyne CB. Immune responses at the maternal-fetal interface. Sci Immunol 2019;4. https://doi.org/10.1126/sciimmunol.aat6114.

[138] Mu Q, Cabana-Puig X, Mao J, Swartwout B, Abdelhamid L, Cecere TE, et al. Pregnancy and lactation interfere with the response of autoimmunity to modulation of gut microbiota. Microbiome 2019;7:105. https://doi.org/ 10.1186/s40168-019-0720-8.

[139] Kirby TO, Ochoa-Repáraz J. The gut microbiome in multiple sclerosis: a potential therapeutic avenue, vol. 6. Basel, Switzerland: Med Sci; 2018. https:// doi.org/10.3390/medsci6030069.

[140] Tong Y, Liu J, Yang T, Kang Y, Wang J, Zhao T, et al. Influences of pregnancy on neuromyelitis optica spectrum disorders and multiple sclerosis. Mult Scler Relat Disord 2018;25:61-5. https://doi.org/10.1016/j.msard.2018.07.006. 